\title{
Colheita mecanizada de soja no Mato Grosso: Perdas devido ao desempenho das
}

\section{colhedoras e aspectos operacionais}

\author{
Mechanized soybean harvest in Mato Grosso: Losses due to harvester performance and operational \\ aspects
}

Cosecha mecanizada de soja en Mato Grosso: Pérdidas devido al desempeño de las cosechadoras Y aspectos operativos

\author{
Rodrigo Sinaidi Zandonadi \\ ORCID: https://orcid.org/ 0000-0001-5623-2204 \\ Universidade Federal de Mato Grosso, Brasil \\ E-mail: zandonadi.rodrigo@gmail.com \\ Solenir Ruffato \\ ORCID: https://orcid.org/0000-0002-9132-6799 \\ Universidade Federal de Mato Grosso, Brasil \\ E-mail: soleruffato@gmail.com
}

\begin{abstract}
Resumo
O estado de Mato Grosso é o maior produtor de grãos do Brasil e poucos são os trabalhos tratando das perdas de soja no momento da colheita sendo geralmente uma avaliação específica, não permitindo uma caracterização do panorama geral do que ocorre no campo. O objetivo com este trabalho foi: (i) realizar um levantamento mais representativo de perdas, devido à colhedora, pela caracterização da frota e das condições de operação; (ii) diagnosticar o uso de tecnologia embarcada e (iii) identificar perdas associadas a problemas operacionais encontrados nas operações visitadas. As perdas devido às colhedoras foram avaliadas utilizando método dos gabaritos, coletando dados relativos às perdas na plataforma e nos mecanismos internos para todas as 64 máquinas avaliadas nas regiões Médio-norte e Nordeste de MT ao longo das safras 13/14 e 14/15. Uso de tecnologia embarcada foi realizado através de formulários assim como a caracterização da frota. As perdas devido a problemas operacionais foram realizadas pontualmente de acordo com os problemas encontrados nas diferentes propriedades visitadas. Verificou-se em mais de $50 \%$ das avaliações que a umidade de grão era maior que 19\%b.u. (considerada acima do ideal), porém uma situação inevitável devida as condições climáticas da época de colheita. Em termos de perdas, 60\% das máquinas apresentaram resultado abaixo do considerado aceitável $\left(60 \mathrm{~kg} \mathrm{ha}^{-1}\right)$ sendo registrado situações de apenas $20 \mathrm{~kg} \mathrm{ha}{ }^{-1}$. Foi possível demonstrar que problemas operacionais encontrados em várias ocasiões, causam maior impacto nas perdas quando comparado com as máquinas avaliadas, porém na maioria dos casos, não são contabilizadas.
\end{abstract}

Palavras-chave: Perda de grãos; Colhedora; Desempenho; Práticas operacionais.

\begin{abstract}
Mato Grosso (MT) is the largest grain producer in Brazil and there are few studies dealing with soybean losses during harvest. The studies are usually specific and does not allow a general overview of what happens in the field. Therefore, the objectives of this study was: (i) accomplish a larger survey about losses, due to the harvester, characterizing the fleet and operation conditions; (ii) identify the usage of embedded technologies and (iii) identify losses associated with operational problems found in fields. The losses due to the harvester were evaluated using the template method, collecting data regarding losses due to the header and internal mechanisms for all 64 machines evaluated in the Mid-North and Northeast regions of MT throughout the 13/14 and 14/15 seasons. Use of embedded technology was accomplished using spreadsheets, as well as harvester fleet characterization. The losses due to operation problems were evaluated according to the specific problems found in the visited properties. It was found that grain moisture content was greater than 19\% (considered above ideal) for more than $50 \%$ of the evaluations. However, this is an inevitable situation due to the weather conditions of MT during soybean harvesting. In terms of losses due to machine, $60 \%$ of the harvesters presented losses bellow the tolerance level $\left(60 \mathrm{~kg} \mathrm{ha}^{-1}\right)$, with situations of only $20 \mathrm{~kg} \mathrm{ha}^{-1}$ being found. It was possible to demonstrate that operational problems encountered on several occasions, have a greater impact on losses when compared to the evaluated machines, but in most cases, they are not considered.
\end{abstract}

Keywords: Grain losses; Combine harvester; Performance; Operational practices. 


\begin{abstract}
Resumen
Mato Grosso (MT) es el mayor productor de granos de Brasil y pocos son los estudios que abordan las pérdidas de soja al momento de la cosecha siendo generalmente una evaluación específica, no permitiendo una caracterización del panorama general de lo que sucede en el campo. El objetivo de este trabajo fue: (i) realizar un levamiento más representativo de pérdidas, por la cosechadora, caracterizando la flota y las condiciones de operación; (ii) diagnosticar el uso de tecnología integrada e (iii) identificar pérdidas asociadas a problemas operativos encontrados en las operaciones visitadas. Las pérdidas debidas a las cosechadoras se evaluaron utilizando el método de plantilla, recolectando datos relacionados con las pérdidas por cabezal y perdidas por cola para las 64 máquinas evaluadas en las regiones Medio Norte y Noreste de MT durante la zafra 13/14 y 14 / 15. El uso de tecnología integrada fue realizado mediante hojas de cálculos, así como la caracterización de la flota. Las pérdidas por problemas operativos se evaluaron puntualmente de acuerdo con los problemas encontrados en las diferentes propiedades visitadas. Se encontró humedad de grano superior al $19 \%$ en más del $50 \%$ de las evaluaciones (consideradas arriba del ideal), ciertamente, una situación ineludible debido a las condiciones climáticas de la época de cosecha. En cuanto a pérdidas, el $60 \%$ de las máquinas presentaron un resultado por debajo de lo considerado aceptable $\left(60 \mathrm{~kg} \mathrm{ha}^{-1}\right)$, registrándose situaciones de tan solo $20 \mathrm{~kg} \mathrm{ha}^{-1}$. Se pudo demostrar que los problemas operativos encontrados en varias ocasiones, tienen un mayor impacto en las pérdidas en comparación con las máquinas evaluadas, pero en la mayoría de los casos no se contabilizan.
\end{abstract}

Palabras clave: Pérdida de grano; Cosechadora; Rendimiento; Prácticas operativas.

\title{
1. Introdução
}

Considerando as previsões de aumento na demanda de alimentos no futuro próximo, qualquer fator de interferência no processo produtivo deve receber a devida atenção, especialmente no que diz respeito às perdas, não só nos diferentes sistemas de produção, assim como nas diferentes fases da cadeia de cada sistema. No caso o Brasil se destaca no tema por ser um dos maiores produtores de alimentos do mundo especialmente no que tange a produção de grãos com destaque para a soja.

Sendo o Mato Grosso o estado brasileiro que lidera o ranking de produção de soja, devida atenção deve ser atribuída às diferentes fases da cadeia produtiva em relação às perdas, seja no campo (pré-colheita ou colheita), no transporte ou no armazenamento. No entanto, apesar das iniciativas relativamente recentes tomadas no levantamento desses fatores, ainda faltam informações para que seja alcançado o bom entendimento da dinâmica das perdas na produção de soja. No que tange as perdas em campo relacionadas a colheita mecanizada, vários trabalhos são encontrados especialmente para as regiões sul e sudeste do país. (Campos et al., 2005; Schanoski et al., 2011; Holtz \& Reis 2013; De Cói et al., 2019) investigando as perdas na colheita mecanizada de soja devido ao desempenho das colhedoras. Além dos trabalhos mencionados, Barbosa et al. (2020) apresentam uma revisão bibliográfica com 22 artigos sobre perdas, sendo que apenas três destes são citados neste artigo e apenas um (Zandonadi et al., 2015) aborda o tema de perdas da colheita de soja no Mato Grosso. Um trabalho correlacionado foi realizado por Gobbi et al. (2014) que avaliaram perdas para comparar o desempenho de plataformas do tipo caracol (condutor helicoidal) e draper (esteira transportadora). O estudo foi conduzido com duas máquinas em uma propriedade em Tabaporã-MT. Zandonadi et al. (2015) conduziram levantamento de perdas em diferentes propriedades do Médio-Norte avaliando dezesseis colhedoras de grãos relatando que $69 \%$ das máquinas avaliadas apresentaram perdas dentro do considerado tolerável (60 $\mathrm{kg} \mathrm{ha}^{-1}$, de acordo com Silveira \& Conte, 2013) e 25\% das colhedoras apresentaram perdas menores que $40 \mathrm{~kg}$ $\mathrm{ha}^{-1}$. Autores relatam que a umidade de grão variou entre 10 a $27 \%$ indicando a grande variação de umidade de grão que pode ocorrer na operação de colheita o Mato Grosso. Litter et al. (2018) avaliaram perdas em diferentes velocidades de deslocamento de uma colhedora BC7500 em uma propriedade no município de Novo Mundo, MT. Os autores não encontram diferença nas perdas para as diferentes velocidades testadas e todos os valores de perdas ficaram acima do aceitável (60 kg $\mathrm{ha}^{-1}$ ). Holtz et al. (2019) avaliaram perdas na colheita mecanizada de soja utilizando diferentes mecanismos na plataforma de corte em uma propriedade em Nova Xavantina-MT. As perdas encontradas estavam dentro do limite aceitável e não encontraram diferença entre diferentes tipos de plataforma. As avaliações foram conduzidas em duas colhedoras New Holland, sendo uma CR 9060 e a outra CR 9080. 
Os trabalhos mencionados abordam uma análise de perdas referente ao desempenho das colhedoras (regulagens dos mecanismos, velocidade de trabalho, condição da cultura, etc.) e não exploram, ou pelo menos não relatam, as perdas causadas por problemas operacionais como: orientação de trabalho em relação à linha da cultura, rastros de operações precedentes à colheita, máquina trabalhando com a plataforma parcialmente preenchida, entre outros. Mesmo na revisão apresenta por Barbosa et al. (2020), esses temas não são abordados. Nota-se, no entanto, que devido as condições de largas extensões de áreas produtivas no Mato Grosso são comumente encontrados problemas operacionais que podem causar perdas tão grande quanto, ou até mesmo maior do que se pode encontrar nas colhedoras e seus respectivos mecanismos. Problemas de rastros de operações que precedem a colheita (ex. pulverizadores e distribuidores de fertilizante), colhedoras trabalhando em um mesmo talhão de maneira desorganizada causando perda significativa de capacidade operacional, além de desperdício de combustível e influência na perda de grãos. Não se encontra na literatura trabalhos que abordem perdas na colheita associados a aspectos operacionais de manejo da cultura, talvez pela dificuldade ou ausência de metodologia estabelecida, diferentemente do método para determinação de perdas advindas da máquina que é amplamente encontrado na literatura (Mesquita \& Gaudêncio, 1982; Silveira \& Conte, 2013; Zandonadi et al., 2021; Mota et al., 2015; Mota et al., 2017).

Em se tratando de avaliação de perdas nas colhedoras de soja, os trabalhos realizados no Mato Grosso foram conduzidos pontualmente e geralmente com número bastante restrito de máquinas avaliadas dificultando a extrapolação para um cenário mais abrangente, não só em termos de desempenho em relação as perdas, mas também em termos de condições de trabalho, como por exemplo, umidade de grãos e velocidade de trabalho, tipicamente encontrados em operações de colheita conduzidas no Mato Grosso.

Sabe-se que a colheita de soja precisa ser realizada de maneira rápida, de forma a possibilitar a implantação da segunda safra, podendo ser principalmente Milho ou Algodão. Tal característica impõe um grande desafio principalmente considerando a época bastante chuvosa em que a colheita da soja transcorre. Diante das dificuldades impostas, várias são as ferramentas embarcadas disponíveis nas colhedoras com o intuito de otimizar o uso da máquina e viabilizar o mapeamento de atributos da lavoura, com a finalidade de melhorar a eficiência do manejo de insumos, podendo até aumentar a produtividade. Ferramentas como sensor de perdas nas colhedoras já eram disponibilizados na década de 90 . Tais sensores servem como referência para um nível de perda pré-estabelecido ao ajustar a sensibilidade, mas ainda não são utilizados para estimar o valor absoluto de perdas.

Com o advento da agricultura de precisão e popularização da eletrônica embarcada, mais sensores foram sendo incorporados nas colhedoras e no final da década de 90, sensores de fluxo de massa e de umidade de grãos começaram a aparecer no Brasil permitindo assim o mapeamento da produtividade instantânea (Queiroz et al., 2000). Começaram a surgir também nessa época, sistemas de direcionamento auxiliado por GPS/GNSS, inicialmente com as conhecidas barras de luz como ferramenta auxiliar, e posteriormente os sistemas de direcionamentos automáticos, hoje popularizados como "piloto automáticos".

O uso das ferramentas acima mencionadas pode contribuir significativamente para a redução das perdas de grãos na operação de colheita, assim como minimizar problemas operacionais que além de proporcionarem perdas de grãos, comprometerem significativamente a capacidade operacional efetiva da frota de máquinas.

Diante do exposto, esse trabalho foi elaborado com os seguintes objetivos: (i) realizar um levantamento mais representativo de perdas, devido à colhedora, na colheita mecanizada de soja no Mato Grosso caracterizando a frota e as condições de operação; (ii) diagnosticar o uso de tecnologia embarcada e (iii) identificar perdas associadas a problemas operacionais encontrados nas operações de colheita visitadas. 


\section{Metodologia}

Seguindo as definições propostas por GIL (2008), este trabalho se caracteriza quanto aos objetivos, como pesquisa descritiva. No que tange a metodologia utilizada, trata-se um estudo de campo.

Várias unidades produtoras de soja localizadas em municípios da região Médio-Norte e Nordeste de Mato Grosso foram visitadas nas safras 2012/2013 e 2013/2014 sendo que no total 64 máquinas foram avaliadas. No intuito de conseguir um diagnóstico do desempenho das colhedoras, em termos de perdas de grãos, na situação de rotina das propriedades, foi requisitado aos operadores que não alterasse nenhuma característica de regulagem ou estratégia de operação para fosse possível caracterizar a condição real de trabalho.

\subsection{Caracterização da frota e das condições de operação e levantamento de Perdas devido aos mecanismos da colhedora}

O método utilizado para coleta de dados foi o clássico proposto por Mesquita e Gaudêncio (1982) em que os dados relativos às perdas na pré-colheita, plataforma de corte, mecanismo interno e total, foram coletados usando um gabarito com uma área equivalente a $2 \mathrm{~m}^{2}$ que envolvia toda a largura da plataforma. Foram coletadas três repetições para cada máquina avaliada. Em cada repetição foram coletados os dados relativos às perdas na plataforma de corte e total. Os dados relativos às perdas na plataforma ( $\mathrm{Pp}$ ) foram coletados (ao longo de toda a largura de corte) na área logo após a plataforma onde não existia material oriundo do descarte dos mecanismos internos (trilha, separação e limpeza) da máquina. Dados relativos à perda total $(\mathrm{Pt}$ ), foram coletados após a passagem da colhedora coletando assim todo o material encontrado (grãos soltos e grãos em vagem) na área do gabarito. As perdas nos mecanismos internos $(\mathrm{Pm})$ foram determinadas pela diferença entre Pt e Pp. As coletas foram conduzidas em pontos do talhão que representassem uma condição de colheita adequada, evitando assim a coleta de dados em áreas de rastros, manobras, arremates, plataforma parcialmente cheia ou condição de plantas acamadas. Cuidados também foram tomados para que os pontos de amostragem fossem determinados em locais em que a máquina estava trabalhando em regime de trabalho estável.

A caracterização da frota se deu com base nos critérios listados a seguir: fabricante, tempo de uso, sistema de trilha e tipo de plataforma. Em termos de fabricantes, foram realizados os registros destes ao coletar os dados de perdas. Em relação ao tempo de uso Balastreire (2005), define que a vida útil de uma colhedora pode ser considerada igual a 10 anos, considerando o uso anual de 400 horas. Devido à dificuldade de conseguir as horas de uso das máquinas junto dos operadores, optou-se por utilizar nesse diagnóstico apenas pelo ano de fabricação da máquina.

As colhedoras foram classificadas quanto ao sistema de trilha, sendo esses o sistema radial (comumente chamada de convencional) e o sistema axial. O sistema de trilha axial se consolidou no mercado brasileiro a partir de 2000 e hoje é predominante no mercado, apesar de existirem máquinas radiais de pequeno porte ainda sendo produzidas. Nesse trabalho, foram identificados os diferentes sistemas e observado a utilização característica na operação de colheita (por exemplo: colhendo curva de nível, arremate ou área de cabeceira).

As plataformas foram classificadas em condutor helicoidal (caracol) e sistemas com esteira transportadora (draper). As plataformas do tipo "draper" (esteira transportadora), introduzidas por volta de 2011, ganharam mercado rapidamente (Nietiedt et al., 2011).

A caracterização das condições de operação foi feita com base na umidade de grãos no momento da colheita e velocidade de operação. Como mencionando anteriormente, o objetivo foi realizar um levamento representativo das condições típicas de trabalho. Não foram alteradas configuração de regulagem das máquinas ou modificado o padrão de operação para a coleta de dados. 


\subsection{O diagnóstico o uso de tecnologia embarcada}

Foram coletados, na medida do possível, informações sobre ferramentas como sistemas de direcionamento automático e sistemas de monitoramento de produtividade. Para cada um dos sistemas, os dados foram agrupados em três classes sendo: máquina equipada, não equipada e equipada e não utilizado.

\subsection{Perdas associadas a aspectos operacionais}

Os aspectos operacionais foram abordados no âmbito das propriedades/talhões visitados. Foram avaliadas 64 colhedoras, porém em praticamente todas as propriedades visitas, contavam com várias máquinas trabalhando em um mesmo talhão. O objetivo dessa parte do trabalho foi conduzir levantamentos pontuais para poder contrastar com as perdas devido aos mecanismos da colhedora.

As principais causas de perdas associados a problemas operacionais observadas nas visitas foram devidos à: rastros (ex. pulverizador e distribuidor de fertilizante); estratégia de alinhamento da pista de colheita (ex. colheita em ângulo ou enviesada); colhedora trabalhando com a plataforma de corte parcialmente cheia e manobras que poderiam ser evitadas. Sendo que as duas últimas situações comprometem consideravelmente a capacidade operacional das colhedoras.

No intuito de chamar a atenção para esses problemas, foram feitas coletas pontuais de maneira que fosse possível estimar as perdas naquela determinada situação para poder contrastar com as perdas encontradas nas colhedoras.

\section{a. Rastros}

Nos rastros deixados nas lavouras foram encontradas plantas adultas em fase de maturação acamadas (condição a) e o esmagamento da planta no início do ciclo impedindo com que esta chegasse no estádio reprodutivo (condição b). Isso dependendo em qual trato cultural foi realizado o rastro. No caso (a), foi demarcado o rastro previamente a passagem da colhedora por $60 \mathrm{~m}$. Depois da passagem da máquina, recolheu-se as vagens que ficaram no local. Para a condição (b), foi também estabelecido uma distância de $60 \mathrm{~m}$ de rastro. Nesse espaço demarcado, foi realizada a mensuração das falhas nas linhas da cultura resultante do esmagamento causado pelas rodas dos equipamentos.

\section{b. Colheita em ângulo ou "enviesada"}

Nessa situação a colhedora não trabalha no mesmo alinhamento da semeadura e os separadores da plataforma, ao cruzar a linhas, acabam por acamar as plantas. Em uma condição em que a máquina fosse trabalhando contra o acamamento, as perdas seriam mínimas, mas nas ocasiões de várias máquinas trabalhando em um mesmo talhão foi comum observar colhedoras trabalhando no sentido do acamamento.

Estimativas pontuais foram feitas em uma passada da colhedora trabalhando a favor do acamamento. Três trechos aleatórios de $2 \mathrm{~m}$ foram marcados antes da colheita e após a passagem da colhedora, e então recolhidas as vagens encontradas nas regiões demarcadas.

\section{c. Colheita com plataforma parcialmente preenchida e manobras que poderiam ser evitadas}

Durante o desenvolvimento do trabalho observou-se certas situações nas operações de colheita que não só favorecem o aumento de perdas de grãos, mas afetam principalmente a eficiência de campo das máquinas. Situações em que a máquina trabalha com a plataforma parcialmente cheia ou que realizam manobras que poderiam ser evitadas em uma operação 
planejada. Estas foram algumas das situações frequentemente encontradas. Nesse caso, não foi possível fazer uma estimativa pontual de perdas para exemplificar, mas foi apresentado uma discussão entorno da problemática.

\section{Resultados e Discussão}

\subsection{Caracterização da frota e das condições de operação e levantamento de Perdas devido aos mecanismos da colhedora}

O fabricante de colhedoras predominante nas propriedades visitadas foi a John Deere, seguido pela marca Case IH (Figura $1 \mathrm{~A})$.

O tempo de uso, sendo um importante parâmetro associado ao desempenho, segundo Carvalho et al. (2005), é apresentado na Figura 1 B, sendo observado que 64\% das máquinas contavam com menos de quatro anos de uso, ou seja, menor que metade da vida útil de 10 anos.

Na Figura 2 são apresentados os resultados relacionados ao sistema de trilha e tipo de plataforma das máquinas avaliadas.

Figura 1. (A) Colhedoras avaliadas de acordo com fabricante. (B) Tempo de uso das máquinas avaliadas.

(A)

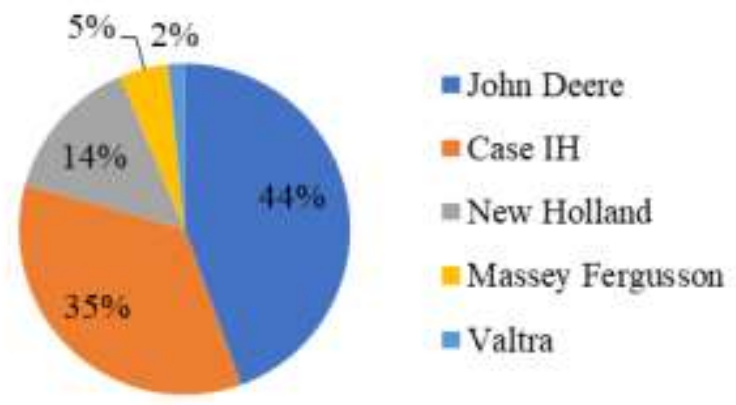

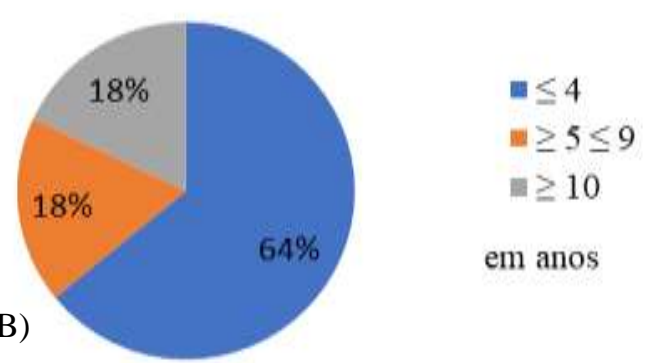

(B)

Fonte: Autores.

Figura 2. Porcentagem das máquinas avaliadas em relação ao sistema de trilha e separação (A) e tipo de plataforma (B).

(A)

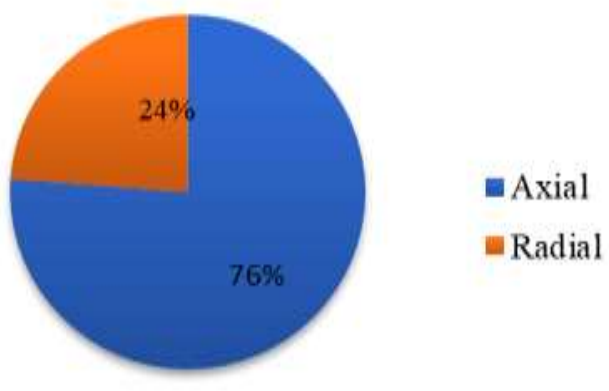

(B)

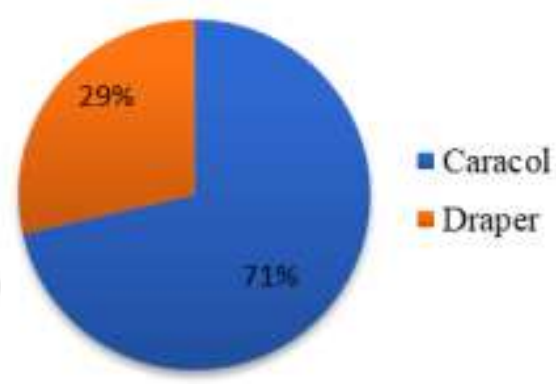

Fonte: Autores.

Geralmente, as máquinas com sistema de trilha radial faziam parte da frota basicamente para conduzir os arremates dos talhões ou fazer a colheita em terraços. Em apenas uma das propriedades visitadas, a frota era predominante do tipo radial.

Em relação à plataforma, todas as máquinas radiais estavam equipadas com plataforma do tipo "caracol" (condutor helicoidal). As máquinas axiais, com menor tempo de uso, estavam equipadas com plataforma "draper", entretanto, foram encontradas plataforma com condutor helicoidal em $71 \%$ das máquinas avaliadas. De acordo com informações publicadas pela 
EMBRAPA (2009) a plataforma de corte e recolhimento é responsável pela maior parte das perdas que ocorrem nas colhedoras de grãos, chegando a representar $80 \%$ das perdas. O estudo mencionado é anterior ao aparecimento do sistema “draper", sendo este, uma evolução para melhoria do desempenho das colhedoras proporcionando redução de perdas e aumento da capacidade operacional (Gobbi et al., 2014), esse tipo de tecnologia passou a ser padrão nas colhedoras axiais de médio e grande porte.

Os resultados relativos às condições de trabalho em que as máquinas avaliadas se encontravam em termos de umidade do grão e de velocidade de trabalho, são apresentados nas Figura 3 e 4, respectivamente. Observa-se que aproximadamente $50 \%$ das máquinas estavam trabalhando com umidade de grãos acima de $19 \%$ b.u. Umidade essa, acima do considerado como ideal para realizar a operação de acordo com a Embrapa (2004) que recomenda que a colheita seja realizada com umidade entre 13 e $15 \%$ b.u. Nota-se, no entanto, que apenas 14\% das máquinas estavam trabalhando com umidade entre 13 e $15 \%$ b.u. Geralmente o pico da colheita de soja, culmina com o período de maior índice pluviométrico, principalmente em situações em que se visa o sucesso da segunda safra a ser implantada. Essa é uma característica muito importante principalmente no que tange o desempenho das colhedoras. Percebe-se, no entanto, a importância de se conduzir ensaios para avaliação de desempenho em condições fora do ideal de umidade de grão.

Figura 3. Condição de umidade de grãos nas avaliações das colhedoras.

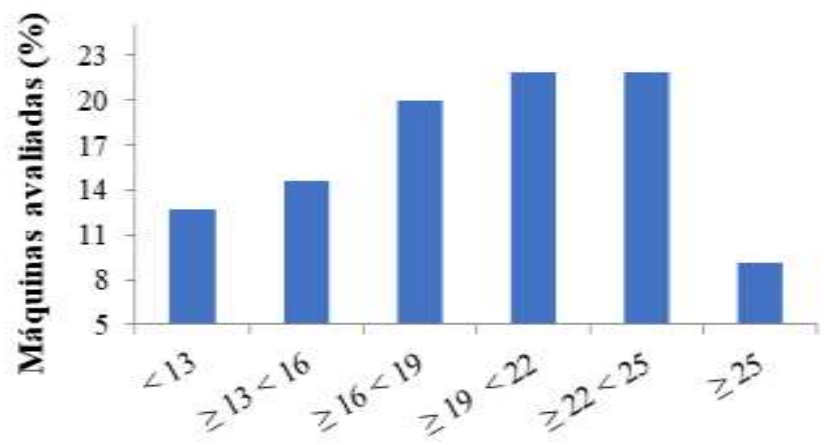

Faixa de umidade de grão (\%) b.u.

Fonte: Autores.

No quesito velocidade, a maior parte das colhedoras estavam trabalhando dentro do que é considerado ideal (4 a $6 \mathrm{~km}$ $\mathrm{h}^{-1}$ ) até porque em condições de alta umidade dos grãos, faz com que a velocidade de trabalho fique limitada. Alguns trabalhos indicam que menores perdas são alcançadas quando a operação é conduzida a velocidades menores que $7 \mathrm{~km} \mathrm{~h}^{-1}$ (Machado et al., 2012; Silva et al., 2013). 
Figura 4. Condição de velocidade de trabalhado nas avaliações das colhedoras de grãos.

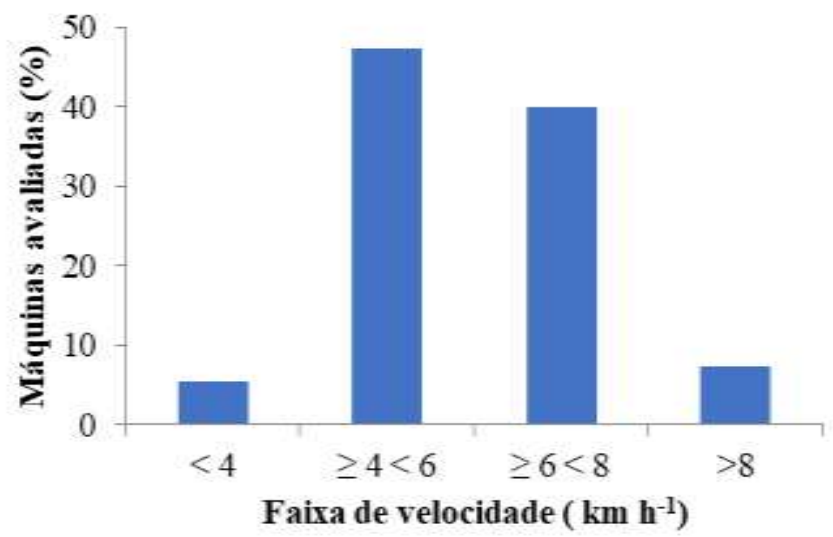

Fonte: Autores.

Os dados de perdas são apresentados nas Figura 5 e 6 para perda total e na plataforma, respectivamente. Observa-se que aproximadamente $60 \%$ das máquinas avaliadas apresentaram perda total dentro do limite aceitável, que segundo Silveira e Conte (2013) é de $60 \mathrm{~kg} \mathrm{ha}^{-1}$. De maneira geral, pode-se dizer um desempenho satisfatório quando comparado com resultados obtidos por Schanoski et al. (2011) onde $79 \%$ das 39 máquinas avaliadas apresentaram perdas maiores que $60 \mathrm{~kg}$ ha-1.

Foram identificadas perdas extremas acima de $120 \mathrm{~kg} \mathrm{ha}^{-1}$, contudo correspondem apenas a $7 \%$ das máquinas avaliadas, e ainda foi possível identificar que essas máquinas encontravam-se colhendo com alta velocidade em combinação com umidade do grão elevada. Nível de perdas abaixo do esperado também foi identificado onde aproximadamente $6 \%$ das avaliações, as máquinas apresentaram perdas menores que $20 \mathrm{~kg} \mathrm{ha}^{-1}$. Ocasiões em que as máquinas se encontravam em condições ideais de trabalho em termos de porte de cultura, clima, sistematização de terreno e obviamente, velocidade de trabalho e regulagem dos mecanismos da colhedora.

A maior ocorrência de perdas na plataforma se deu na faixa de 20 a $40 \mathrm{~kg} \mathrm{ha}^{-1}$ com aproximadamente $35 \%$ das máquinas avaliadas. Fazendo a razão entre as duas maiores frequências ocorridas para perda total $\left(40\right.$ a $\left.60 \mathrm{~kg}^{-1}\right)$ e perda na plataforma (20 a $40 \mathrm{~kg} \mathrm{ha}^{-1}$ ) resulta o percentual de $66,7 \%$ corroborando com o fato de que geralmente a perda na plataforma é responsável pela maior parte das perdas ocorridas em uma colhedora. O fato de $71 \%$ das máquinas estarem equipadas com plataformas do tipo "caracol" ainda contribuem com a elevado percentual de perdas ocorridas neste ponto.

Figura 5. Resultado de perda total nas avaliações conduzidas.

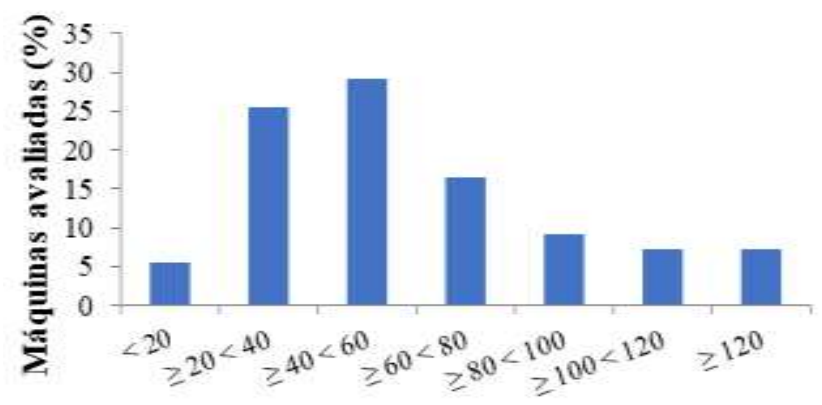

Faixa de perda total $\left(\mathrm{kg} \mathrm{ha}^{-1}\right)$

Fonte: Autores. 
Figura 6. Resultado de perdas na plataforma de corte e recolhimento.

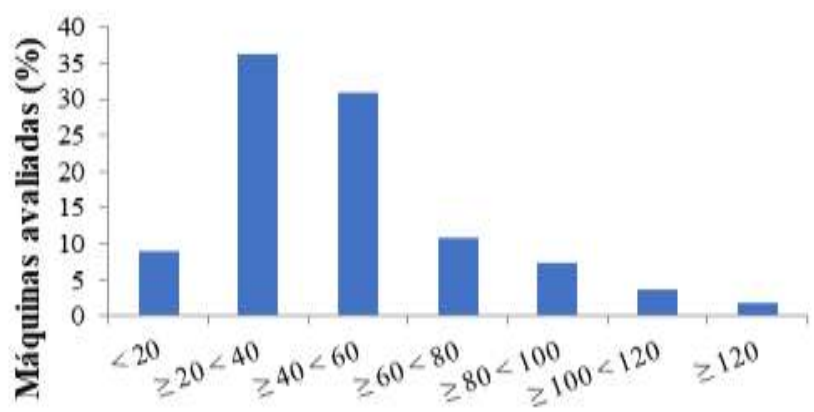

Faixa de perda na plataforma $\left(\mathrm{kg} \mathrm{ha}^{-1}\right)$

Fonte: Autores.

\subsection{Diagnóstico do uso de tecnologia embarcada}

No quesito de tecnologia embarcada, os resultados apresentados na Figura 7 mostram que a evolução da adoção das tecnologias de direcionamento automático e de monitores de produtividade não foi muito expressiva, visto que mais de $60 \%$ das máquinas não estavam equipadas. Foi observado que pelos $35 \%$ das colhedoras estavam equipadas com algum tipo de sistema de direcionamento, mas apenas $8 \%$ estavam sendo efetivamente utilizados. Boa parte dos operadores das máquinas dos $16 \%$ que não estavam utilizando a ferramenta, relataram que utilizavam o sistema apenas para a cultura do milho.

Em relação aos monitores de produtividade, $27 \%$ das máquinas avaliadas estavam equipadas, mas o sistema não estava sendo utilizado para monitorar a produtividade da soja, devido as dificuldades que envolviam, desde calibração dos sensores até processamento para tratamento de dados para a geração dos mapas de produtividade.

Figura 7. Tecnologia embarcada englobando sistemas de direcionamento automático (A) e monitores de produtividade (B).

(A)

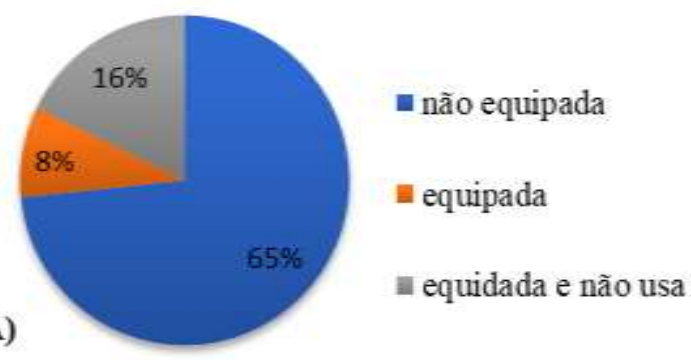

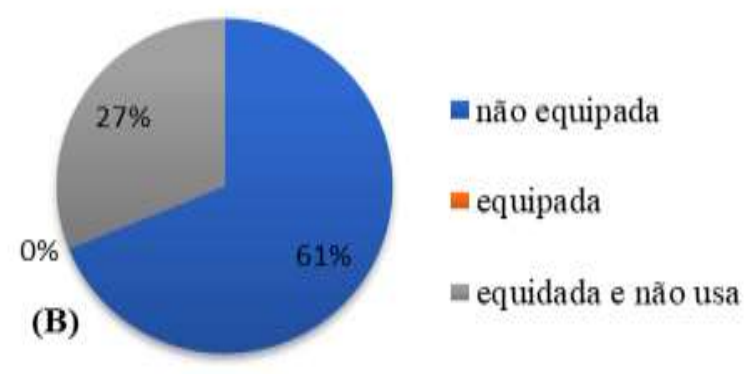

Fonte: Autores.

\subsection{Perdas associadas a aspectos operacionais}

\section{a. Rastros}

Os danos causados por rastros podem resultar perdas por acamamento ou extinção das plantas por esmagamento (Figura 8), o que depende de quando o rastro é feito pela primeira vez e quantas vezes um determinado equipamento passou por aquele rastro. Observe que as perdas ocorrem pelo fato de a máquina não ter recolhido as plantas acamadas ou pelo fato de a planta ter sido esmagada, e assim não atingir o estádio de maturação. 
Figura 8. Exemplo de perdas causados por rastro. (A) característica de plantas extintas nas linhas de semeadura e algumas plantas acamadas; (B) característica de plantas acamadas nas linhas de semeadura. (C) material encontrado após a passagem da colhedora na condição (A) em que as plantas sofreram cortes duplos pela barra de corte e não foram recolhidas e (D) material encontrado no campo após a passagem da colhedora na condição (B) em que as plantas não foram cortadas e recolhidas pela plataforma.
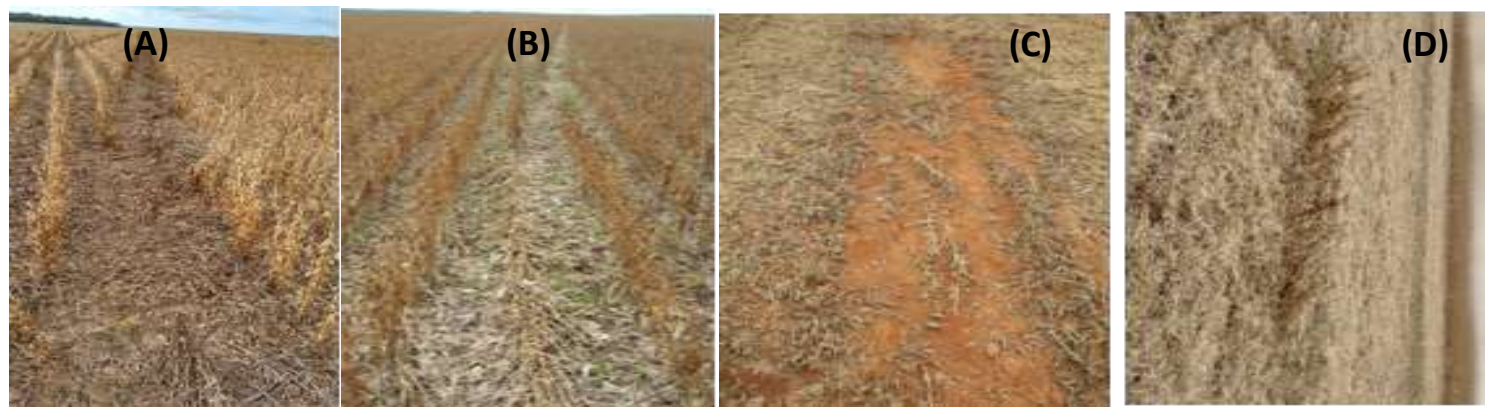

Fonte: Autores.

No levantamento conduzido, considerando as plantas cortadas e não recolhidas, acumulou-se nos 60 m de rastro, 999 g de grãos que se encontravam ainda em vagens. Considerando a largura de $30 \mathrm{~m}$ da barra do pulverizador (porte comum pulverizador nas propriedades visitas), um hectare trabalhado irá produzir aproximadamente 667 m de rastro. No entanto, aproximadamente $11,1 \mathrm{~kg} \mathrm{ha}^{-1}$ perdidos.

Nesses $60 \mathrm{~m}$ de rastros, a soma de linhas cruzadas que foram esmagadas e plantas extintas foi de aproximadamente 45 m (75\% de esmagamento). Logo, em 667 m de rastros feito em 1 ha, na condição avaliada, tem-se o equivalente a $500 \mathrm{~m}$ de plantas que não atingiram o estádio reprodutivo. Considerando produtividade média de $60 \mathrm{sc} \mathrm{ha}^{-1}$ de uma cultura estabelecida com espaçamento entre linhas de $0,5 \mathrm{~m}$, são $90 \mathrm{~kg} \mathrm{ha}^{-1}$ que deixaram de ser produzidos. Levando-se em consideração o custo dos insumos 8,4 sc ha-1 (IMEA, 2019) desperdiçados nesses $500 \mathrm{~m} \mathrm{ha}^{-1}$ de plantas extintas, são mais $12,6 \mathrm{~kg}$ ha ${ }^{-1}$ que podem ser contabilizados nas perdas. Pode-se observar que na condição de avaliação de rastros, um total de $113,7 \mathrm{~kg} \mathrm{ha}^{-1}(1,9 \mathrm{sc}$ ha-1) de perdas de grãos foi contabilizada.

\section{b. Colheita em ângulo ou colheita "enviesada"}

Na Figura 9A é apresentado um exemplo da condição em que a máquina está colhendo a favor do acamamento na estratégia de colheita em ângulo. Na Figura B e C pode ser observado o detalhe do acamamento e as plantas que não foram recolhidas pela máquina respectivamente.

A média de grãos em vagem coletados nos trechos demarcados resultou em 60,9 $\mathrm{g} \mathrm{m}^{-1}$. Considerando a plataforma de 30 pés $(9,1 \mathrm{~m})$, são aproximadamente $1098 \mathrm{~m}$ lineares por ha trabalhado. Considerando produtividade média de $60 \mathrm{sc}^{-1} \mathrm{em}^{-1}$ uma cultura estabelecida com espaçamento entre linhas de $0,5 \mathrm{~m}$, são $197,7 \mathrm{~kg} \mathrm{ha}^{-1}$ (3,3 sc ha-1) que ficaram no campo. É importante ressaltar que essa perda foi observada na ocasião em que a máquina trabalhava a favor do acamamento e que quando a máquina trabalha contra o acamamento essa perda é minimizada. No entanto, em várias ocasiões ao longo dos levantamentos, foram observadas máquinas colhendo a favor das plantas que se encontravam acamadas. Percebeu-se ainda que o acamamento da cultura era piorado na medida que se aumentava a instabilidade de direcionamento da máquina. 
Figura 9. Exemplo de colheita realizada em ângulo diferente a linha de semeadura (A), detalhe do acamamento (B) e detalhe do material não recolhido pela máquina $(\mathrm{C})$.

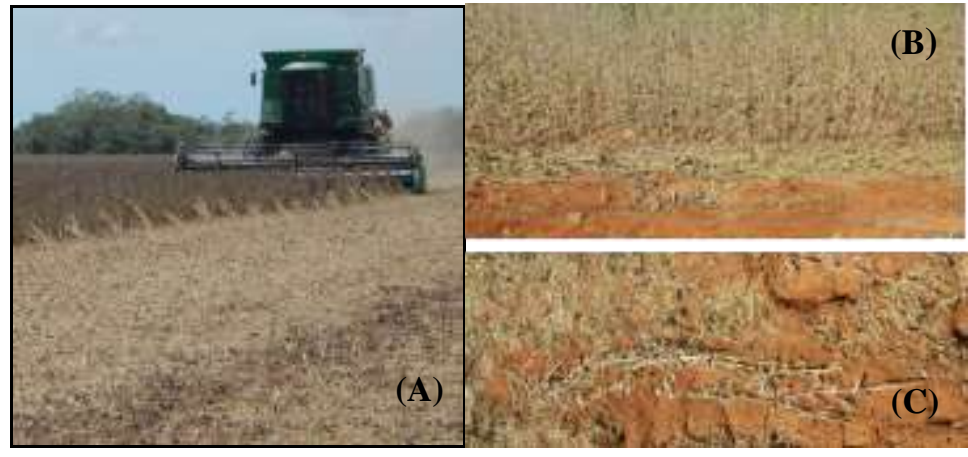

Fonte: Autores.

\section{c. Colheita com plataforma parcialmente preenchida e manobras que poderiam ser evitadas}

São apresentados na Figura 11, exemplos de situações que favorecem o aumento de perdas de grãos e afetam a eficiência de campo da frota de máquinas, sendo essas plataformas de corte e recolhimento incompletas e manobras que poderiam ser evitadas.

É sabido que o sistema de trilha e separação de uma colhedora precisa ser ajustada para trabalhar com um determinado fluxo de massa. Caso esse fluxo de massa seja alterado, o efeito trilhador sobre o material sendo processado será modificado, resultando na mudança do desempenho em termos de perdas e danos mecânicos conforme dados de desempenho apresentados na Figura 10 (Kutizbach \& Quick, 1999). Obviamente ao se trabalhar com a plataforma parcialmente preenchida e ao realizar manobras, o regime de fluxo de massa é modificado, proporcionando assim o aumento não só de perdas de grãos como também proporciona aumento de danos mecânicos.

Figura 10. Desempenho relativo a perdas e danos mecânicos causados no sistema de trilha e separação em função do fluxo de massa.
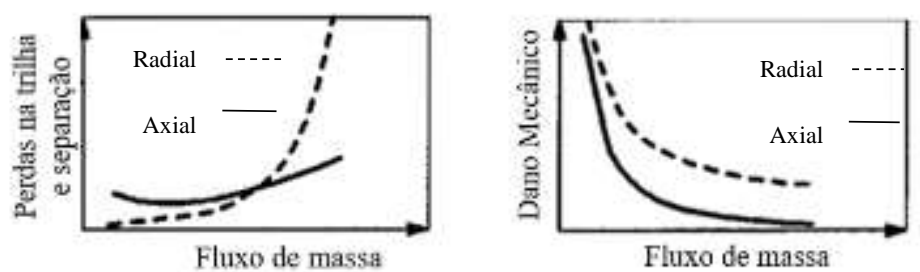

Fonte: Adaptado de Kutizbach e Quick, (1999).

Vale ressaltar que nas condições de plataforma parcialmente preenchida, o operador tende a aumentar a velocidade de trabalho e isso aumenta consideravelmente as perdas ocorridas na plataforma. Geralmente, espera-se que situações demonstradas na Figura 11, aconteça somente ao finalizar um talhão, porém, em várias ocasiões foram observadas essa situação recorrente ao longo da operação dentro de um mesmo talhão. Em determinada propriedade, ao observar a operação de um talhão, foi estimado que pelo menos $25 \%$ da área havia sido trabalhada dessa maneira (colhedora trabalhando com plataforma praticamente vazia). Note que além dos problemas de perdas e danos mecânicos, as máquinas gastam mais tempo e combustível por precisar transitar com parte da plataforma vazia e fazendo manobras desnecessárias. 
Figura 11. Exemplo de situações de operação que favorecem mudança no desempenho da máquina em relação às perdas, danos mecânicos, desperdício de combustível e comprometimento da capacidade operacional da frota.

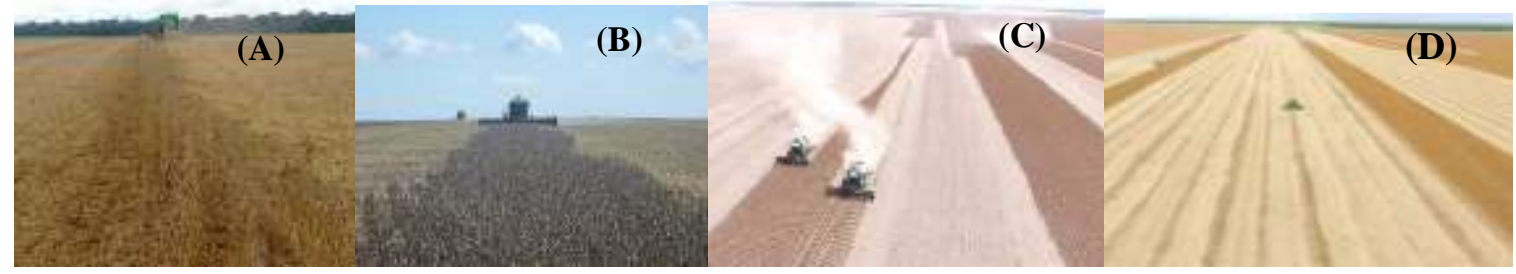

Fonte: Autores.

Os problemas acima mencionados podem ser minimizados com um bom planejamento da operação da colheita e treinamento dos operadores. Com um pouco de esforço, é possível implementar técnicas de tráfego controlado utilizando as tecnologias de orientação e direcionamento que são comumente embarcados nas máquinas e assim elevar o padrão de operação no nível otimizado. Como relatado no tópico (ii), $16 \%$ das colhedoras se encontram com sistema de direcionamento automático e não estavam sendo utilizados. Além de minimizar os problemas de perdas, o ganho obtido na eficiência de campo e consequentemente capacidade operacional, traz grande impacto tanto na redução de perdas quanto na eficiência de uso de máquinas. Silva et al. (2015) realizaram um levantamento e apontam que a falta de planejamento na colheita em determinadas ocasiões no Mato Grosso, colhedoras chegam a perder 38,8\% do tempo de trabalho apenas no processo de descarregamento do graneleiro (sem contar as manobras essenciais da operação). Considerando mais 15\% de tempo perdido necessários para manobras em campo a eficiência de campo dessas colhedoras seria de aproximadamente 46\%. Em contrapartida, resultados de trabalhos conduzidos em larga escala, apontam que é possível utilizar planejamento de colheita associado a técnicas de tráfego controlado e elevar nível de eficiência de campo para mais de $80 \%$ podendo chegar a $90 \%$ e situações particulares de formato de talhão (Silva et al., 2017; Koelln \& Zandonadi, 2018).

\section{Considerações Finais}

Pode-se concluir com este levantamento que as condições de trabalho típicas encontradas no Mato Grosso são bem diferentes das consideradas ideais para a operação de colheita em termos de umidade sendo que mais de 50\% das avaliações mostraram que o grão estava sendo colhido com mais de 19\%b.u. de umidade. Isso é um fator decisivo a ser considerado na concepção e projeto de uma colhedora e merece a devida atenção em relação aos trabalhos de pesquisa de campo.

A velocidade de trabalho encontrada, esteve de maneira geral, próximo do considerado como ideal, talvez pela própria dificuldade de se conseguir trabalhar com as colhedoras em condições de umidade de grão elevada.

Em termos de tecnologia embarcada, muito tem ainda a ser explorado e desenvolvido da "porteira pra dentro". Existem muitas ferramentas interessantes disponíveis no mercado e muito poucas sendo efetivamente utilizadas no campo.

As colhedoras apresentaram em maior parte, bom desempenho no que tange as perdas de grãos (menos $60 \mathrm{~kg} \mathrm{ha}^{-1}$ ) sendo que $60 \%$ das 64 máquinas avaliadas apresentaram perdas dentro do tolerável, mesmo não trabalhando na condição considerada ideal em termos de umidade de grão. O fato de encontrar máquinas trabalhando com perdas bem abaixo do limite aceitável (menor que $20 \mathrm{~kg} \mathrm{ha}^{-1}$ ), indica o potencial das colhedoras modernas em serem eficientes quando trabalham nem condições próximas do ideal.

Os resultados e discussões apresentados ao entorno dos problemas operacionais (rastros na lavoura, orientação da colheita, planejamento de manobras) apontam fatores que causam perdas mais expressivas do que aquelas relacionadas ao desempenho (regulagem e manutenção) das colhedoras para as regiões estudadas. Enquanto $60 \%$ das máquinas avaliadas 
apresentaram perdas menores que $60 \mathrm{~kg} \mathrm{ha}^{-1}$ (considerado tolerável), somente amassamento por rastros das operações precedentes à colheita, proporcionaram $114 \mathrm{~kg} \mathrm{ha}^{-1}$ de perdas nas avalições apresentadas neste trabalho. São problemas que podem ser minimizados ou até mesmo sanados se houver melhor planejamento da operação e fazendo uso efetivo de ferramentas disponíveis que em determinadas situações, como apresentadas nesse trabalho, estão embarcadas nas máquinas e não estão sendo utilizadas.

Por fim, fica claro a importância em se levar em consideração também os aspectos operacionais da colheita quando se trata de perdas de grãos no campo. Futuros estudos devem abordar uso de ferramentas e estratégias que podem auxiliar na minimização das perdas de grãos e também melhorar a capacidade operacional da frota de colheita.

\section{Agradecimentos}

À Associação de Produtores de Soja e Milho de Mato Grosso (APROSOJA/MT) pelo apoio financeiro que viabilizou esse trabalho e aos produtores da região Médio-Norte e Nordeste de Mato Grosso que colaboraram com a realização do trabalho.

\section{Referências}

Balastreire, L. A. (2005). Máquinas Agrícolas. Manole.

Barbosa, E. J. A., Alessio, D. R. M., Velho, J. P., Costa Filho, J., \& Costa, N. L. (2020). Pre-harvesting, harvesting, and transport of soybean to brazilian ports: Bioeconomic losses. Research, Society and Development, 9(9), e744997878. https://doi.org/10.33448/rsd-v9i9.7878

Carvalho, F. A., Cortez, J. W., Silva, R. P.; \& Zago, M. S. (2005). Perdas na colheita mecanizada da soja no triângulo mineiro. Revista Nucleus, 3(1), 89-94. https://doi.org/10.3738/nucleus.v3i1.423

Campos, M. A. O., Silva, R. P., Filho, A. C., Mesquita H. C.B., \& Zabani, S. (2005). Perdas na colheita mecanizada de soja no Estado de Minas Gerais, Engenharia Agrícola, 25(1), 207-213.

DE Cói, A. C. M., Dotto, L., Modolo, A. J., \& Sgarbossa, M. (2019). Perdas na colheita mecanizada no sudoeste do Paraná. Agrarian Academy, 6(1), 237245. https://doi.org/10.18677/Agrarian_Academy_2019a23

EMBRAPA. (2004) Tecnologia de produção de soja. Região central do Brasil.

EMBRAPA. (2009). Cultivo de Soja no Cerrado de Roraima. Sistema de produção.

GIL, A. C. (2008). Como elaborar projetos de pesquisa. (4a ed.), Atlas.

Gobbi, F. T., Zandonadi, R. S., \&Pinto, F. A. C. (2014). Desempenho de colhedoras de grãos utilizando plataforma de corte com condutor helicoidal e esteira transportadora. Congresso Brasileiro de Engenharia Agrícola.

Holtz, V., \& dos Reis, E. F. D. (2013). Perdas na colheita mecanizada de soja: uma análise quantitativa e qualitativa. Revista Ceres, 60(3), 347353. https://doi.org/10.1590/S0034-737X2013000300007

Holtz, V., Grellmann, D. H., Azevedo, R. O., Koester, B. E. G., Jardim, C. C. S., Massola, M. P., \& Reis, R. G. E. (2019). Perdas na colheita mecanizada de soja utilizando diferentes mecanismos na plataforma de corte. Pubvet Medicina veterinária e zootecnia. 13(2), 16. https://doi.org/10.31533/pubvet.v13n2a261.1-6

IMEA - Instituto Mato Grossense de Economia e Agropecuária. (2019) Custo de produção soja safra $2019 / 20$.

Koelln, F. H. B. \& Zandonadi, R. S. (2018). Estudo da Logística na Colheita Mecanizada de Soja na Região Noroeste Mato-grossense. Simpósio Matogrossense de mecanização agrícola e agricultura de precisão.

Kutzbach, H. D., \& Quick G. R. Harvesters and Threshers: Grain. in: Stout, B. A., Cheze, B., (1999). Handbook of Agricultural Engineering, Volume III: Plant Production. CIGR.

Litter, F. A., Carneiro, M. A., Oss, L. L., \& Ferreira, F. M. (2018). Levantamento de perdas na colheita mecanizada de soja em diferentes velocidades de deslocamento. Simpósio Mato-grossense de mecanização agrícola e agricultura de precisão.

Machado, T. A., Santos, F. L., Cunha, J. P. B., Cunha, D. A., \& Coelho, L. M. (2012). Perdas na plataforma de corte de uma colhedora combinada de grãos na colheita de soja. Engenharia na agricultura, 20(6), 537-543. https://doi.org/10.13083/reveng.v20i6.378

Mota, B. L.; Zandonadi, R. S.; Silva A. J. S.; Viola, M. (2015). Protótipo de um Sistema Mecanizado para Coleta de Dados de Perdas e Distribuição de Palhada na Colheita Mecanizada de Soja. In: Jubileu de Ouro da SBEA (pp. 1-7). SBEA 
Research, Society and Development, v. 10, n. 5, e5810514216, 2021

(CC BY 4.0) | ISSN 2525-3409 | DOI: http://dx.doi.org/10.33448/rsd-v10i5.14216

Mota, B. L.; Zandonadi, R. S.; Ferray, W. Z.; Silva, A. J. S. (2017). Sistema Mecanizado para Coleta de Dados de Perdas e Dis tribuição de Palha na Colheita Mecanizada de Soja. In: A importância da Engenharia Agrícola para a segurança alimentar (pp. 1-10). SBEA.

Mesquita, C.M., \& Gaudêncio, C.A. (1982). Medidor de perdas na colheita de soja e trigo. Comunicado Técnico. EMBRAPA-CNPSo.

Nietiedit, G. H., Schlosser, J. F., \& Booler, W. (2011). Draper Hiflex. Revista Cultivar Máquinas. 26-30.

Queiroz, D. M., Dias, G. P., \& Mantovani, E. C. (2000). Agricultura de Precisão na Produção de Grãos. Agricultura de Precisão.

Schanoski, R., Righis, E. Z., \& Werner, V. (2011). Perdas na colheita mecanizada de soja (Glycine max) no município de Maripá - PR. Revista Brasileira de Engenharia Agrícola e Ambiental,15(11), 1206-1211. http://dx.doi.org/10.1590/S1415-43662011001100015

Silva, A. J. S., Zandonadi, R. S., Barbosa, F. S., \&Viola, M. (2015) Estudo de caso: Influência do método de descarregamento no rendimento operacional de colhedoras de grãos na colheita de soja. Congresso Brasileiro de Engenharia Agrícola

Silva, R. P., Silva, B. M. S, Barrozo, L.M., Salum, J. D., Rosa, M. S., \& Gomes, D. P. (2013). Perdas qualitativas na colheita mecanizada de sementes de soja. Ciências Agrárias, 34(2), 477-484.

Silva, A. J. S., Zandonadi, R. S., Mota, B. L., \& Ferrari, W. (2017). Instrumentação para o estudo da logística de campo em operação de colheita mecanizada de grãos. Congresso Brasileiro de Engenharia Agrícola, 1-4.

Silveira, J. M., \& Conte, O. (2013). Determinação de perdas na colheita de soja: copo medidor da Embrapa. EMBRAPA-CNPSo).

Zandonadi, R. S., Ruffato, S., \& Figueiredo, Z. N. (2015) Perdas na colheita mecanizada de soja na região médio-norte de mato grosso: safra 2012/2013. Revista Nativa, 3(1), 64-66. http://dx.doi.org/10.31413/nativa.v3i1.2035

Zandonadi, R. S., Mota, B. L., \& Ruffato, S. (2021). Métodos para avaliação de perdas nas colhedoras. Fichas Técnicas, 1(2), 1-4. https://www.mtciencia.com.br/vol-1-no-8-ano-2021/ 